CASE REPORT

\title{
Subdural haematoma associated with an arachnoid cyst after repetitive minor heading injury in ball games
}

\section{A K Demetriades, A W McEvoy, N D Kitchen}

Br J Sports Med 2004;38:e8 (http://www.bjsportmed.com/cgi/content/full/38/4/e8). doi: 10.1136/bjsm.2003.005710

We report the case of a chronic subdural haematoma caused by repetitive heading of a football which led to the diagnosis of a middle fossa arachnoid cyst. The association between arachnoid cysts and subdural haematoma is discussed as are safety implications in sporting injuries.

A rachnoid cysts are developmental anomalies often diagnosed in childhood as incidental findings on imaging. They occasionally produce symptoms because of expansion or haemorrhage. Such cysts have been observed to be related to a higher risk of subdural haematoma. ${ }^{1}$ Sports related head injuries occasionally cause subdural haematomas which may be the first presentation of a previously undiagnosed arachnoid cyst. The potentially serious effects of such haematomas suggests that participants in professional sports with a high incidence of head injuries should be alerted to this possible risk. Implications of screening with computed tomography (CT) scans in high risk sports and also the more specific question of whether individuals with known arachnoid cysts should be allowed to compete in such sports are discussed.

\section{CASE REPORT}

A 24 year old university student was admitted complaining of a 6 week history of increasing headache and nausea, especially in the morning, unsteadiness, and 2 days of vomiting and mild right sided weakness. There was no history of head trauma on direct questioning, other than a report of feeling slightly lightheaded after a twice weekly football practice. This feeling would subside slowly over the next $24 \mathrm{~h}$. Computed tomography revealed a large subdural haematoma lying superficial to a left middle fossa arachnoid cyst, and midline shift (fig 1). At operation via a burr hole craniotomy a large chronic subdural haematoma was confirmed and evacuated. Clinical recovery was satisfactory with no persistent neurological deficit. In a subsequent outpatient follow up appointment, the patient volunteered that in retrospect he had linked the headaches he had after each football session with his propensity for frequently heading the ball during the game.

\section{DISCUSSION}

Arachnoid cysts arise from a developmental aberration involving duplication or splitting of the arachnoid membrane. ${ }^{1}$ They contain clear cerebrospinal fluid (CSF) with a normal biochemical and cellular content. If the protein content is mildly elevated this may suggest isolation from the CSF pathway, whereas if xanthochromia is also present this may be suggestive of previous intracystic haemorrhage. Arachnoid cysts can present at any age with symptoms that are often mild even with large lesions. Headache and craniomegaly due to cyst expansion and hydrocephalus occur with cysts of any location (sylvian fissure, interhemispheric fissure, sellar/suprasellar, quadrigeminal cistern, vermis, clivus, spinal intra/extradural). Seizures suggest a supratentorial location.

Arachnoid cysts of the middle fossa commonly present under the age of 20 years. They are found more commonly in males (4:1) and it has been suggested that they are commoner on the left side. ${ }^{2}$ Diagnosis is often made incidentally on radiological imaging. Patients may present with symptoms of raised intracranial pressure or, as is more commonly the case in children, with a cranial deformity resulting from pressure erosion of the cyst within the calvarium. Although secondary arachnoid cysts can form as a result of trauma or infection, which may split the arachnoid layer with oedema, the majority of middle fossa arachnoid cysts are congenital anomalies. ${ }^{2}$ It is thought that during the developmental stage of CSF space formation a pulsatile CSF flow originating from the choroid plexus could lead to invagination of the perimedullary mesenchyme and thus the formation of a false passage. ${ }^{3}$

The association between arachnoid cysts and subdural haematomas was first noted in 1971. ${ }^{2}$ Although no explanation for this predisposition has been proven, theories have been suggested. ${ }^{4}$ As arachnoid cysts are less compliant than normal brain tissue, the amount of intracranial "cushioning" during trauma is reduced with an increased likelihood of bridging veins to bleed. Alternatively, due to the different composition of arachnoid cyst fluid compared to normal CSF, pressure may be transferred more readily and in magnified form, which may lead to rupture of the bridging veins or of the vessels within the cyst wall.

Subdural haematomas associated with arachnoid cysts have been observed in several sports. Such soccer related injury has only been reported twice before: on one occasion the ball related head injury was forceful, ${ }^{5}$ but in another, ${ }^{6}$ as in our case, it seems to have arisen after repetitive "routine heading" of the ball during play. With recent studies in soccer suggesting that concussional head injury may lead to neuropsychological damage later on in life, ${ }^{7}$ and with more cases of chronic subdural haematomas associated with heading injuries, the risk may have to be reassessed in the case of susceptible individuals, such as patients with arachnoid cysts.

Subdural haematomas have been observed in several sports, from ball games like basketball ${ }^{8}$ to non-contact sports like race walking. ${ }^{9}$ Soccer related brain injury is uncommon. However, a recent coroner's ruling in south Staffordshire on the death at the age of 59 of a professional footballer, "famous for regularly heading the ball", linked it to "industrial disease". ${ }^{10}$ Since arachnoid cysts are recognised as conferring an increased susceptibility for a triad of complications including midline shift, subdural haematoma,

Abbreviations: CSF, cerebrospinal fluid; CT, computed tomography 

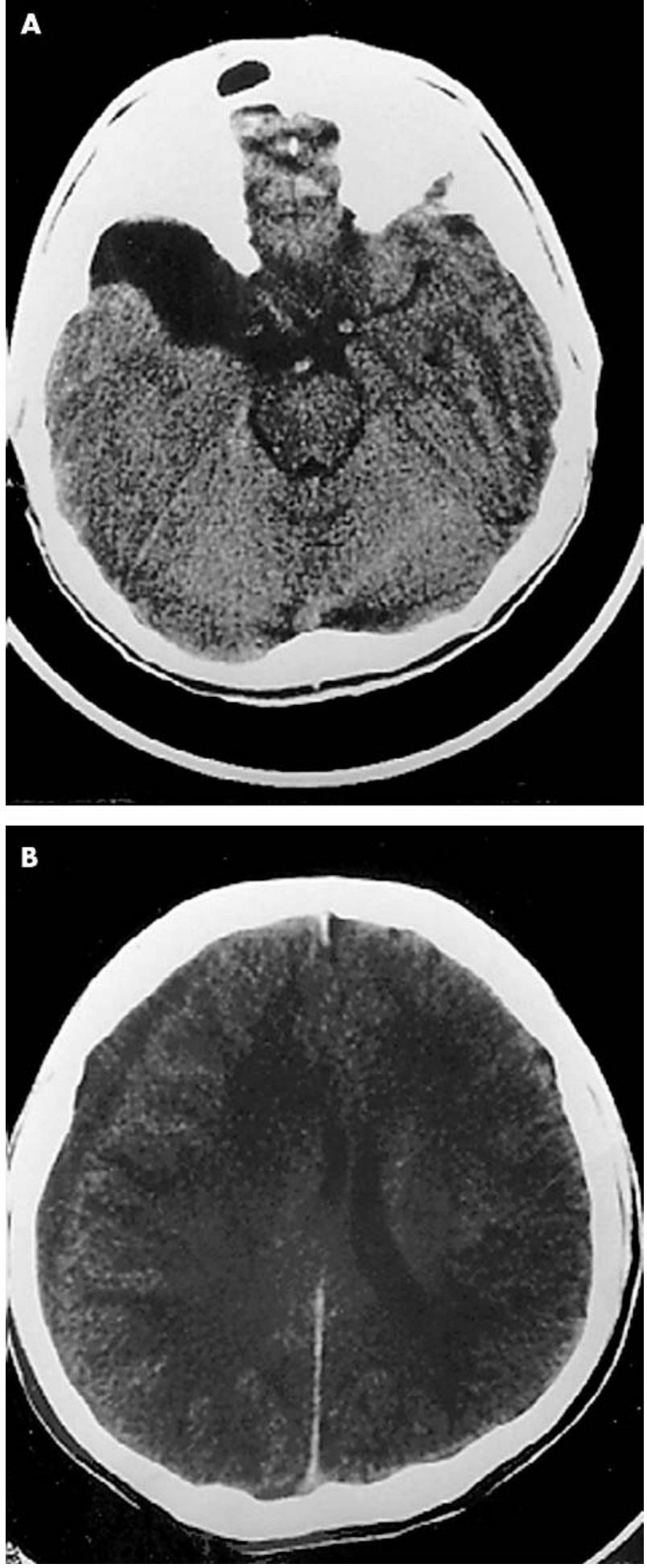

Figure 1 Axial CT scan of the patient's head showing a low attenuation lesion $(A)$ in the right temporal fossa in keeping with an arachnoid cyst. There is a right isodense subdural collection (B) which is compressing the right lateral ventricle. The sulci are less prominent on the right.

and intracystic haemorrhage, implications arise regarding the regulation of participation in sports recognised to have an increased risk of head injury.

Specifically, should individuals with a known diagnosis of an arachnoid cyst be allowed to compete in contact sports? In such sports, like boxing, not only do affected individuals run the risk of an acute intracystic bleed but also the chronic risk

\section{Take home message}

- Soccer related concussion is common and carries a risk of intracranial injury and haematoma.

- The presence of an arachnoid cyst increases the risk of significant injury including subdural haematoma, intracystic haemorrhage, and midline shift.

- Although screening athletes for such abnormality is not cost-effective, sports physicians should have a high index of suspicion when athletes present with a history of recurrent or protracted concussion-like symptoms.

of a subdural haematoma. Does boxing in the presence of an arachnoid cyst lead to an increased susceptibility for development of a chronic subdural haematoma later on in life? And should athletes in high risk sports be screened, with $\mathrm{CT}$, for the presence of arachnoid cysts?

These issues are difficult to tackle. The Amateur Boxing Association of England would not allow an individual to continue after such a diagnosis, but does not require a CT scan during the athlete's initial medical examination. ${ }^{11}$ Furthermore, measures are not uniform in other amateur or professional bodies internationally. Although screening in selected sport communities would allow a diagnosis before a complication occurred, such a proposition would be extremely costly and therefore potentially obstructive, not only to the professional sports bodies and funding agencies, but also to the athletes themselves. As we do not know the true population of athletes with such pathology their relative increase in risk remains undetermined.

Recent data suggest that soccer related head injury is a common cause of sports related concussion, with documented risk of intracranial injury and haematoma. While screening for arachnoid cysts in sports may not be costeffective, physicians involved in sports medicine, amateur or professional, should be made specifically aware of this condition and should have a high index of suspicion. A protracted history but consistently linked to repetitive head injury should alert the physician to the possibility of an arachnoid cyst.

\section{Authors' affiliations}

A K Demetriades, A W McEvoy, N D Kitchen, Victor Horsley Department of Neurosurgery, National Hospital for Neurology and Neurosurgery, Queen Square, London, UK

Conflict of interest: none declared.

Correspondence to: Andreas K Demetriades, 10 Reed Place, Old Avenue, West Byfleet, Surrey KT14 6AX, UK; andreas.demetriades@ doctors.org.uk

Revised version received 23 May 2003

Accepted for publication 16 July 2003

\section{REFERENCES}

1 Starkman SP, Brown TE, Linell EA. Cerebral arachnoid cysts. J Neuropathol Exp Neurol 1958;17:484-500.

2 Robinson RG. Congenital cysts of the brain: arachnoid malformations. Progr Neurosurg 1971;4:133-74.

3 Starkman SP, Brown TC, Linell EA. Cerebral arachnoid cysts. J Neuropathol Exp Neurol 1958;17:484-500.

4 Page A, Paxton RM, Mohan D. A reappraisal of the relationship between arachnoid cysts of the middle fossa and chronic subdural haematoma. J Neurol Neurosurg Psychiatry 1987;50(8):1001-7.

5 Prabhu VC, Bailes JE. Chronic subdural hematoma complicating arachnoid cyst secondary to soccer-related head injury: case report. Neurosurgery 2002;50(1):195-8. 
6 Kawanishi A, Nakayama M, Kadota K. Heading iniury precipitating subdural hematoma associated with arachnoid cysts - two case reports. Neurol Med Chir (Tokyo) 1999;39(3):231-3.

7 Matser EJ, Kessels AG, Lezak MD, et al. Neuropsychological impairment in amateur soccer players. JAMA 1999;282(10):971-3.

8 Keller TM, Holland MC. Chronic subdural haematoma, an unusual injury from playing basketball. Br J Sports Med 1998;32(4):338-9.
9 Carmont MR, Mahattanakul W, Pigott T. Acquisition of a chronic subdural haematoma during training for competitive race walking? Br J Sports Med 2002;36(4):306-7.

10 Eaton L. Coroner cites football as reason for brain injury. $\mathrm{Br} J \mathrm{Med}$ 2002;325:1133.

11 The Medical Commission of the Amateur Boxing Association of England Limited. Medical Aspects of Amateur Boxing. 4th ed. London, UK: Amateur Boxing Association of England Limited, 2002.
吕

os

은

\

局

듬

$\frac{5}{7}$

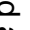

$\overrightarrow{0}$

.

o

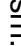

응

ம

비

인

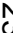

气

용

망

ฏ

ญి

윽

굴

흥.

을

ชิ

N 